\title{
Carbon nanowalls grown by microwave plasma enhanced chemical vapor deposition during the carbonization of polyacrylonitrile fibers
}

Jiangling Li, Shi Su, Lei Zhou, Vojtěch Kundrát, Andrew M. Abbot, Fajer Mushtaq, Defang Ouyang, David James, Darren Roberts, and Haitao Ye

Citation: Journal of Applied Physics 113, 024313 (2013); doi: 10.1063/1.4774218

View online: https://doi.org/10.1063/1.4774218

View Table of Contents: http://aip.scitation.org/toc/jap/113/2

Published by the American Institute of Physics

\section{Articles you may be interested in}

Raman spectra of carbon nanowalls grown by plasma-enhanced chemical vapor deposition

Journal of Applied Physics 97, 104320 (2005); 10.1063/1.1900297

Fabrication of vertically aligned carbon nanowalls using capacitively coupled plasma-enhanced chemical vapor deposition assisted by hydrogen radical injection

Applied Physics Letters 84, 4708 (2004); 10.1063/1.1762702

Initial growth process of carbon nanowalls synthesized by radical injection plasma-enhanced chemical vapor deposition

Journal of Applied Physics 106, 094302 (2009); 10.1063/1.3253734

Three-dimensional carbon nanowall structures

Applied Physics Letters 90, 123107 (2007); 10.1063/1.2715441

Electrical conduction control of carbon nanowalls

Applied Physics Letters 92, 213103 (2008); 10.1063/1.2936850

Free-standing subnanometer graphite sheets

Applied Physics Letters 85, 1265 (2004); 10.1063/1.1782253

\section{AIP| $\left.\right|_{\text {Applied id Physics }} ^{\text {Jaun }}$ SPECIAL TOPICS}

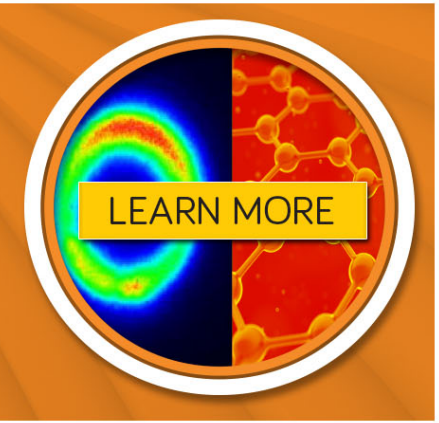




\title{
Carbon nanowalls grown by microwave plasma enhanced chemical vapor deposition during the carbonization of polyacrylonitrile fibers
}

\author{
Jiangling Li, ${ }^{1}$ Shi Su, ${ }^{1}$ Lei Zhou, ${ }^{2}$ Vojtěch Kundrát, ${ }^{1}$ Andrew M. Abbot, ${ }^{1}$ Fajer Mushtaq, ${ }^{3}$ \\ Defang Ouyang, ${ }^{4}$ David James, ${ }^{5}$ Darren Roberts, ${ }^{5}$ and Haitao $\mathrm{Ye}^{1, \mathrm{a})}$ \\ ${ }^{1}$ School of Engineering and Applied Science, Aston University, Birmingham B4 7ET, United Kingdom \\ ${ }^{2}$ Department of Metallurgy and Materials, University of Birmingham, Birmingham B15 2TT, United Kingdom \\ ${ }^{3}$ Department of Mechanical Engineering, ETH Zurich, Zurich 8092, Switzerland \\ ${ }^{4}$ School of Life and Health Science, Aston University, Birmingham B4 7ET, United Kingdom \\ ${ }^{5}$ Thermo Fisher Scientific, Stafford House, Hemel Hempstead HP2 7GE, United Kingdom
}

(Received 29 October 2012; accepted 17 December 2012; published online 10 January 2013)

\begin{abstract}
We used microwave plasma enhanced chemical vapor deposition (MPECVD) to carbonize an electrospun polyacrylonitrile (PAN) precursor to form carbon fibers. Scanning electron microscopy, Raman spectroscopy, and Fourier transform infrared spectroscopy were used to characterize the fibers at different evolution stages. It was found that MPECVD-carbonized PAN fibers do not exhibit any significant change in the fiber diameter, whilst conventionally carbonized PAN fibers show a 33\% reduction in the fiber diameter. An additional coating of carbon nanowalls (CNWs) was formed on the surface of the carbonized PAN fibers during the MPECVD process without the assistance of any metallic catalysts. The result presented here may have a potential to develop a novel, economical, and straightforward approach towards the mass production of carbon fibrous materials containing CNWs. (C) 2013 American Institute of Physics.

[http://dx.doi.org/10.1063/1.4774218]
\end{abstract}

\section{INTRODUCTION}

Carbon nanowalls (CNWs) first reported by Wu et al. ${ }^{1}$ consist of nano-graphite domains with a few tens of graphene layers, which stand on a substrate and can be described as vertically aligned carbon sheets with an average thickness of several nanometers. ${ }^{2}$ CNWs have high aspect ratio, large surface area, chemical stability, and mechanical strength. This unique shape and structure offered by CNWs has stimulated not only fundamental studies of transport properties and gas absorption but also various applications in electron field emitters, catalyst supports in fuel cells, and electrodes in lithium ion batteries. ${ }^{2}$

Since the discovery of CNWs, various groups have reported the synthesis of these remarkable structures and performed systematical characterisation using electron microscopy and Raman spectroscopy. Wu et al. reported that the formation of CNWs on the various catalyzed substrates, including stainless steel, $\mathrm{Cu}, \mathrm{Si}, \mathrm{GaAs}, \mathrm{SiO}_{2} / \mathrm{Si}$, and sapphire in $\mathrm{CH}_{4}$ and $\mathrm{H}_{2}$ system using microwave plasma enhanced chemical vapor deposition (MPECVD). ${ }^{1}$ Kurita et al. documented that the CNWs were grown on the $\mathrm{Ni}$, or $\mathrm{Ni} / \mathrm{Cr}$ catalyzed substrates at the substrate temperature of $550-800{ }^{\circ} \mathrm{C}$ by using MPECVD. ${ }^{3}$ Furthermore, the fabrication of CNWs on two-dimensional substrates without using catalysts by chemical vapor deposition (CVD) was also reported by many other authors. ${ }^{4-6}$ Shang et al. synthesized uniform carbon flakes with a thickness of less than $20 \mathrm{~nm}$ on $\mathrm{Si}$ substrates at the substrate temperature of $400-700^{\circ} \mathrm{C}$ by hot-filament chemical vapor deposition (HFCVD) using

\footnotetext{
a) Author to whom correspondence should be addressed. Electronic mail: h.ye@aston.ac.uk.
}

the mixture of $\mathrm{C}_{2} \mathrm{H}_{2}$ and $\mathrm{H}_{2} \cdot{ }^{4}$ Wang et al. produced freestanding carbon nanosheets (CNS) on substrates, such as $\mathrm{Si}$, $\mathrm{W}, \mathrm{Mo}, \mathrm{Zr}, \mathrm{Ti}, \mathrm{Hf}, \mathrm{Nb}, \mathrm{Ta}, \mathrm{Cr}, 304$ stainless steel, $\mathrm{SiO}_{2}$, and $\mathrm{Al}_{2} \mathrm{O}_{3}$ without catalysts or special substrate treatment by using radio-frequency plasma enhanced chemical vapor deposition (RF-PECVD). ${ }^{5}$ Lisi et al. deposited CNWs on carbon paper at growth temperature of $700^{\circ} \mathrm{C}$ in $\mathrm{CH}_{4} / \mathrm{He}$ system using HFCVD. ${ }^{6}$ To the best of our knowledge, most of the work reported so far is limited to two-dimensional substrates and the use of a catalyst is essential in the case of the CVD process. In this paper, we report the growth of CNWs on the carbonized polyacrylonitrile (PAN) fibers without any catalysts during the MPECVD process for the first time.

In the current commercial market, $90 \%$ of the carbon fibers (CFs) are thermally converted from stabilized PAN fiber precursors via high temperature carbonization. ${ }^{7}$ Our original motivation was to convert PAN fibers into carbon fibers using the MPECVD technique. Therefore, we implemented a novel method of utilizing microwave plasma CVD technology coupled with electromagnetic radiation to produce carbon fibers from stabilized PAN fiber precursors, in order to avoid the high costs associated with the conventional carbonization process. ${ }^{8}$ To this end, we have compared the MPECVD induced carbonization process with the conventional furnace carbonization process. The electrospun PAN fibers have been carbonized into carbon fibers during the MPECVD process. In addition, a coating of CNWs was formed on the surface of CFs during the MPECVD process without the assistance of any metallic catalysts. The morphology and chemical structural evolution of the PAN fibers produced from the electrospinning technique were investigated in detail. 


\section{EXPERIMENTAL}

\section{A. Materials}

PAN powders with average molecular weight of 150 000 and $N, N$-dimethylformamide (DMF) solvent were purchased from Scientific Polymer Products and Fisher Scientific, respectively. All chemicals were used without further purification. A predetermined amount of PAN powders was added into DMF at room temperature. After 3-h ultrasonication in air, a homogeneous PAN solution with a concentration of $15 \%(\mathrm{w} / \mathrm{v})$ was formed (ultrasonic processor: Hielscher UP400S).

\section{B. Fabrication of electrospun PAN fiber with various methods}

Electrospinning technique appears to be a highly flexible approach to produce fiber precursors from various materials, and is suitable for both academic research as well as massproduction for industrial purpose. ${ }^{9}$ It has been used here for the PAN fiber fabrication. As-prepared PAN solution was transferred into a $20 \mathrm{ml}$ syringe and connected to blunt metallic needle $(21 \mathrm{G})$ with inner diameter of $0.495 \mathrm{~mm}$ via a plastic tubing. The non-woven electrospun PAN fiber was collected on $\mathrm{Al}$ foil with the following conditions: applied voltage of $15 \mathrm{kV}$, tip-to-collector distance of $20 \mathrm{~cm}$, and flow rate of $1.5 \mathrm{ml} / \mathrm{h}$. In Figure 1 , sample a is the electrospun PAN fibers collected on Al foil.

\section{Treatments of electrospun PAN fiber}

In order to retain fiber morphology in the subsequent heat-treatments, the electrospun PAN fibers were stabilized at $270^{\circ} \mathrm{C}$ in air for $1 \mathrm{~h}$ using a tube furnace (Carbolite, Sheffield, UK). In Figure 1, sample b is the stabilized PAN fibers. For the comparison purpose, the stabilized PAN fibers were further carbonized by two different methods: (1) conventional furnace carbonization and (2) MPECVD carbonization. In the conventional approach, the stabilized PAN fibers were heated from room temperature to $1000^{\circ} \mathrm{C}$ with a

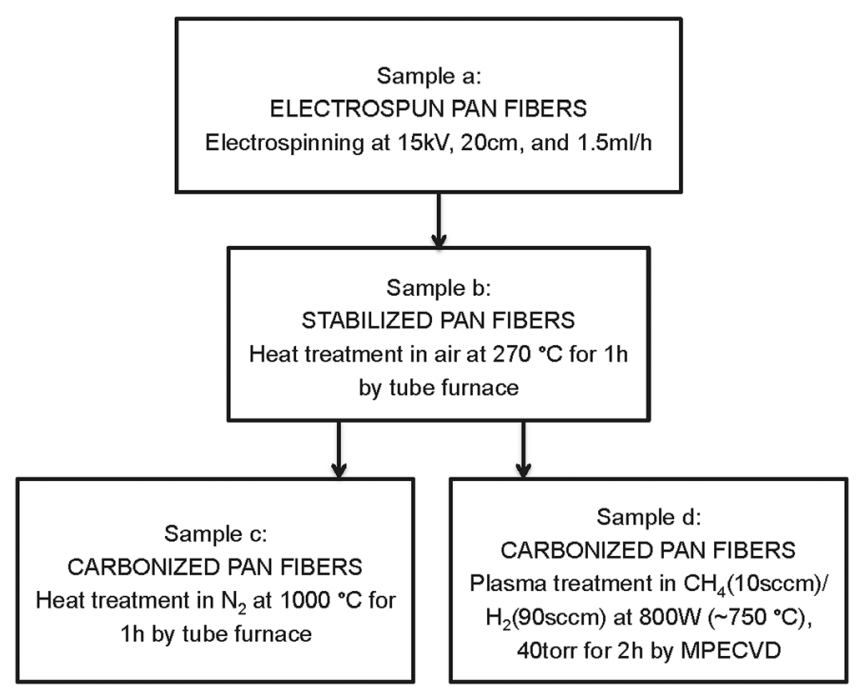

FIG. 1. The evolution process of PAN fibers via various treatments. heating rate of $10^{\circ} \mathrm{C} / \mathrm{min}$, and then held at $1000^{\circ} \mathrm{C}$ for $1 \mathrm{~h}$ with the presence of $\mathrm{N}_{2}$ flow. In the latter case, the stabilized PAN fiber was placed in the ASTeX5010 MPECVD chamber (Seki Technotron, $2.45 \mathrm{GHz}, 1.5 \mathrm{~kW}$ ). Initially, a hydrogen plasma was ignited at the following conditions: microwave power of $800 \mathrm{~W}$, gas pressure of 10 Torr, and $\mathrm{H}_{2}$ flow rate of 90 standard cubic centimeter per minute $(\mathrm{sccm})$. After $5 \mathrm{~min}, \mathrm{CH}_{4}$ gas at the flow rate of $10 \mathrm{sccm}$ was fed into the hydrogen plasma to form $\mathrm{CH}_{4} / \mathrm{H}_{2}$ gas mixtures. Stabilized microwave plasma was formed at an optimized condition as shown below: microwave power of $800 \mathrm{~W}$, gas pressure of 40 Torr, and $\mathrm{CH}_{4} / \mathrm{H}_{2}$ flow ratio of $10 \mathrm{sccm} / 90$ sccm. The carbonization was processed at this condition for $2 \mathrm{~h}$. The substrate temperature was about $750{ }^{\circ} \mathrm{C}$, which was recorded by an infrared thermometer (model: Williamson Pro 92-40-C, range: $475-1475^{\circ} \mathrm{C}$ ). In Fig. 1, samples c and $\mathrm{d}$ are the carbonized PAN fibers by the furnace process and the MPECVD process, respectively.

\section{Characterisation}

The morphology of the four samples was examined by scanning electron microscopy (SEM, JEOL, JSM-7000 F). Due to the nonconductive nature, the electrospun PAN fibers (sample a) and the stabilized PAN fibers (sample b) were gold coated before SEM characterization, using sputter coater (emscope, SC 500). The carbonized PAN fibers (sample $\mathrm{c}$ and sample d) are electrical conductive and therefore were used directly for SEM imaging without any precoating. The functional groups of PAN at different stages were characterized by Fourier transform infrared spectroscopy (FTIR, Nicolet iS5). The chemical structure of the PAN fibers evolved with various treatments was investigated by Raman spectroscopy. The excitation laser wavelength of $532 \mathrm{~nm}$ (Thermo Scientific DXR Raman Microscope) was used.

\section{RESULTS AND DISCUSSION}

\section{A. SEM observation}

Fig. 2 shows SEM images of PAN fibers at different evolution stages. Fig. 2(a) shows the SEM image of the PAN fibers produced by electrospinning demonstrating high uniformity with an average fiber diameter of $644 \pm 76 \mathrm{~nm}$. Fig. 2(b) shows the SEM image of the PAN fibers after the stabilization process. It can be seen that the fibers shown in Figs. 2(a) and 2(b) are similar in size. The only notable difference in the present study is that the color of fibers changed from white (for sample a) to dark brown associated with a slight mass loss (for sample b). The above observations are in agreement with other reports, reflecting that the infusible ladder like polymer structure is established after the fiber stabilization in air. ${ }^{7,10,11}$ Figs. 2(c) and 2(d) show the SEM images of furnace carbonized PAN fibers and MPECVD carbonized fibers, respectively. It can be seen that no sign of fiber melting is found in either sample. In the case of furnace carbonized PAN fibers, the average fiber diameter is significantly reduced to $433 \pm 63 \mathrm{~nm}$ as shown in Fig. 2(c). The dramatic reduction in fiber dimension is likely to be 

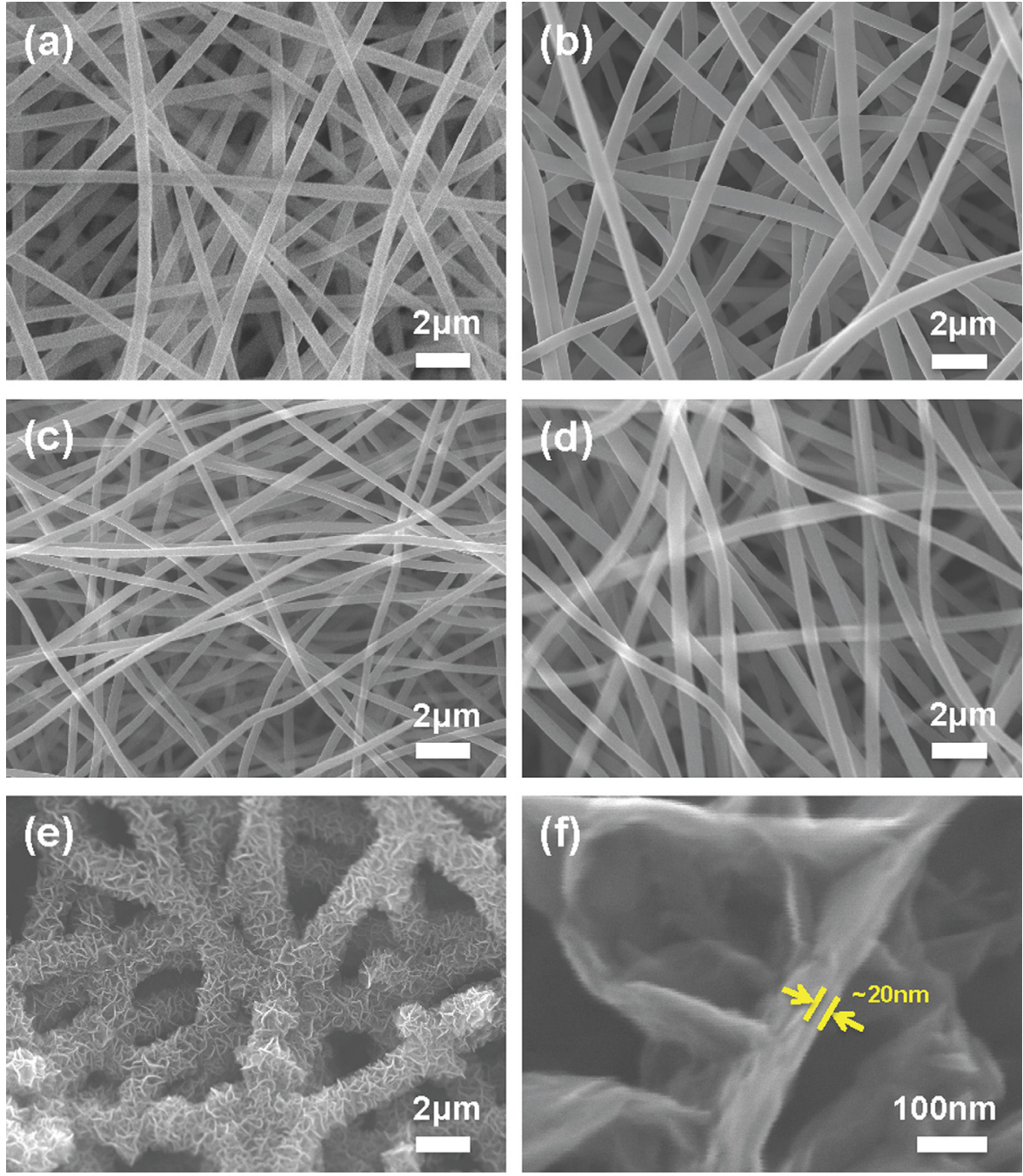

FIG. 2. SEM images PAN fibers at various stages: (a) electrospun PAN fibers, (b) stabilized PAN fibers, (c) furnace carbonized PAN fibers, (d) MPECVD carbonized PAN fibers, (e) MPECVD carbonized PAN fibers with CNWs coatings, and (f) closer view of CNWs at higher magnification. associated with the reaction and evolution of various gases, such as $\mathrm{H}_{2} \mathrm{O}, \mathrm{N}_{2}$, and $\mathrm{HCN}$, which ultimately lead to the formation of carbon fibers. ${ }^{11}$ In contrast, little change in the fiber diameter has been found in the case of the MPECVD carbonized PAN fiber as shown in Fig. 2(d). According to literature, higher carbonization temperature is likely to promote the shrinkage of fiber diameter. Panapoy et al. reported that the fiber diameter was decreased from $275 \mathrm{~nm}$ to $208 \mathrm{~nm}$ by increasing carbonization temperature from $800^{\circ} \mathrm{C}$ to $1000{ }^{\circ} \mathrm{C}^{12}$ Zhou et al. also concluded that average fiber diameter was reduced from $250 \mathrm{~nm}$ to $220 \mathrm{~nm}$ as carbonization temperature increased from $1000^{\circ} \mathrm{C}$ to $1800^{\circ} \mathrm{C}$. ${ }^{11}$ In the case of our present study, the MPECVD carbonization process was carried out at the temperature around $750{ }^{\circ} \mathrm{C}$, which is significantly lower than the conventional furnace carbonization process normally carried out at $1000^{\circ} \mathrm{C}$. This might be able to explain the difference of the fiber diameters between samples $\mathrm{c}$ and $\mathrm{d}$. However, temperature difference may not be the only reason responsible for the observed phenomena. The different physical and chemical nature of these two carbonization processes can also be considered as alternative possibility causing the fiber diameter discrepancy.

In the case of sample $d$, apart from the successful MPECVD fiber conversion from the stabilized PAN fibers to
CFs, interestingly, we have found a layer of "carbon" species on the top of the carbonized PAN fiber as shown in Figs. 2(e) and 2(f). Such carbon species, known as CNWs, have been previously reported to grow on thin films substrates by the CVD methods. ${ }^{1,3-6}$ Fig. 2(e) shows that CNWs were uniformly grown on the surface of the carbonized PAN fibers simultaneously during the MPECVD carbonization process. Fig. 2(f) shows the SEM image of CNWs at higher magnification. It can be seen that the as-grown CNWs consist of multiple nanosheets with a thickness of approximately $20 \mathrm{~nm}$, grown in the direction perpendicular to the fibers. Zhu et al. have reported that the vertical growth of CNS happens after the base layer is established. ${ }^{13}$ The induction-time in planar nucleation and growth is taken place within 2-4 min and the base layer of graphitic sheets grown parallel to the substrate surface is estimated to be $1-15 \mathrm{~nm} .{ }^{13}$ Wang et al. have characterized that the CNS less than $1 \mathrm{~nm}$ thick is consisted of two or three graphene layers by using TEM. ${ }^{5}$ The much more layers of graphene sheet obtained for the current CNWs are expected as a result of long deposition time, as Hiramatsu et al. have found that increasing deposition time (up to $3 \mathrm{~h}$ ) leads to the increase in the CNW thickness. ${ }^{14}$ Therefore, the lesser layers of graphene sheet should be easily obtained by reducing the CVD processing time, 
although changing other parameters such as gas reactant ratio, pressure, and substrate conditions is also considered useful. $^{15}$

\section{B. FTIR studies}

In order to understand the surface chemistry and relevant functional groups, FTIR spectroscopy was used to characterize the samples. Fig. 3 shows the FTIR spectra of PAN at different stages: as-received PAN powders, electrospun PAN fibers, stabilized PAN fibers, furnace carbonized PAN fibers, and MPECVD carbonized PAN fibers both without and with CNWs coating. Fig. 3(a) shows the characteristic FTIR peaks of PAN powders. It can been seen that there is a strong peak located at $2242 \mathrm{~cm}^{-1}$ which corresponds to nitrile group $(\mathrm{C} \equiv \mathrm{N}){ }^{16,17}$ Other peaks located at $2938 \mathrm{~cm}^{-1}$, $1453 \mathrm{~cm}^{-1}, 1357 \mathrm{~cm}^{-1}$, and $1249 \mathrm{~cm}^{-1}$ are corresponding to the vibrations of the aliphatic $\mathrm{CH}$ groups $\left(\mathrm{CH}, \mathrm{CH}_{2}\right.$, and $\left.\mathrm{CH}_{3}\right) .{ }^{18} \mathrm{~A}$ weak peak located at $1623 \mathrm{~cm}^{-1}$ was assigned to amide group. ${ }^{18}$ Fig. 3(b) shows the FTIR spectrum of the electrospun PAN fiber. In comparison with Fig. 3(a), it is found that a new peak at $1667 \mathrm{~cm}^{-1}$ appears, which is associated with $\mathrm{C}=\mathrm{O}$ bond. ${ }^{19}$ The presence of this $\mathrm{C}=\mathrm{O}$ peak implies that the residual DMF exists in the PAN fibers, due to the incomplete DMF evaporation during the electrospinning process. ${ }^{19}$

Fig. 3(c) shows the FTIR spectrum of the stabilized PAN fibers. It can be seen that after the fiber stabilization, the intensity of the peak associated with nitrile group and aliphatic $\mathrm{CH}$ groups has reduced significantly. In addition, some other new FTIR peaks appear, which are located at $1700 \mathrm{~cm}^{-1}(\mathrm{C}=\mathrm{O}), 1582 \mathrm{~cm}^{-1}(\mathrm{a} \operatorname{mix}$ of $\mathrm{C}=\mathrm{N}, \mathrm{C}=\mathrm{C}$, and $\mathrm{N}-\mathrm{H}$ groups), and $805 \mathrm{~cm}^{-1}(\mathrm{C}=\mathrm{C}-\mathrm{H}){ }^{20}$ These dramatic changes in the FTIR spectra imply that the chemical structure of PAN fibers has undergone cyclization, crosslinking, dehydrogenation, as well as oxidation. The result shows an excellent agreement with the published literatures. ${ }^{10,18}$

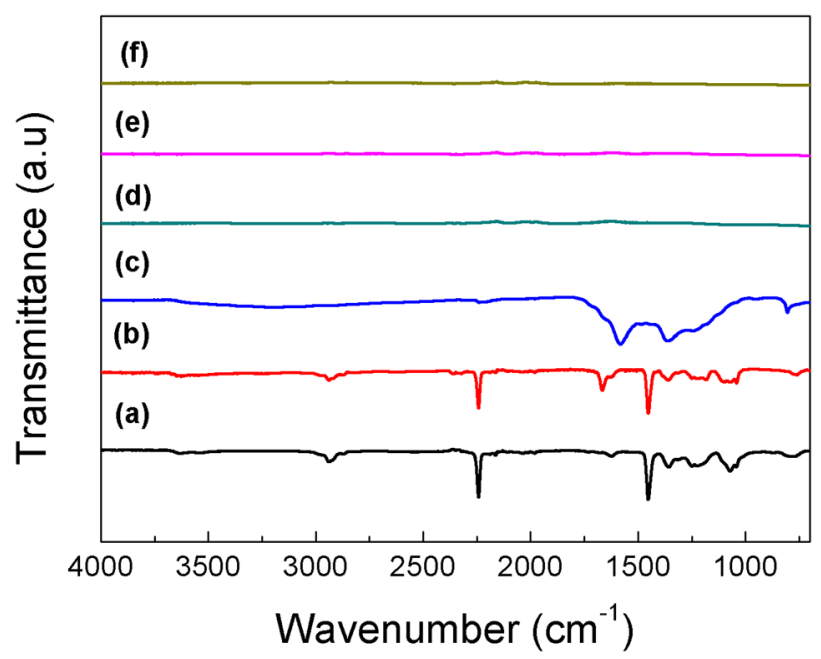

FIG. 3. FTIR spectra of PAN at various stages: (a) as-received PAN powders, (b) electrospun PAN fibers, (c) stabilized PAN fibers, (d) furnace carbonized PAN fibers, (e) MPECVD carbonized PAN fibers, and (f) MPECVD carbonized PAN fibers with CNWs coatings.
Figs. 3(d)-3(f) show the FTIR spectra of the carbonized PAN fibers by both conventional furnace and MPECVD, respectively. It can be seen that there are few functional groups present in the FTIR spectra. This is due to the very high absorbance of carbon products. ${ }^{18}$

\section{Raman investigation}

Raman spectroscopy is one of the powerful tools for characterizing the structural properties of carbonaceous materials. Fig. 4 shows Raman spectra of PAN fibers at four different stages. Fig. 4(a) shows Raman spectrum of electrospun PAN fibers. It can be seen that there is a broad Raman peak centered at $1552 \mathrm{~cm}^{-1}$. The broadness of the Raman band suggests that electrospun PAN fibers lack ordered arrangements of PAN molecules. Similar results were reported by Sutasinpromprae et al., who attributed low crystallinity of the electrospun PAN fibers to (1) the insufficient crystallization time of PAN molecules before solvent vaporization and (2) the fiber structure frozen-in caused by the very short in-flight time of the charged jet (i.e., $\sim 1 \mathrm{~ms}$ ). ${ }^{21}$ It was reported that the electrospun PAN fibers without any treatment exhibit an almost featureless Raman spectrum. ${ }^{10}$

Fig. 4(b) shows the Raman spectrum of the stabilized PAN fibers. It can be seen that there are two main bands observed at $1374 \mathrm{~cm}^{-1}$ and $1567 \mathrm{~cm}^{-1}$, respectively. The former corresponds to $D$ band which is associated with disordered turbostratic structures, whereas the latter corresponds to $G$ band which is attributed to the ordered graphitic structures. ${ }^{11}$ The Raman peak position of $D$ band and $G$ band observed in our study was in agreement with the results by Zhang et al., who reported the $D$ band and $G$ band positioned at $1370 \mathrm{~cm}^{-1}$ and $1580 \mathrm{~cm}^{-1}$ in the stabilized PAN fibers under the conditions of $300{ }^{\circ} \mathrm{C}$ for $30 \mathrm{~min} .{ }^{10} \mathrm{It}$ is known that the ratio of the peak intensity of $D$ band $\left(I_{D}\right)$ and $G$ band $\left(I_{G}\right)$, denoted as $R$-value, can be used to correlate the balance among the disorder and crystalline character in the carbon materials (i.e., higher $R$-value indicates lower

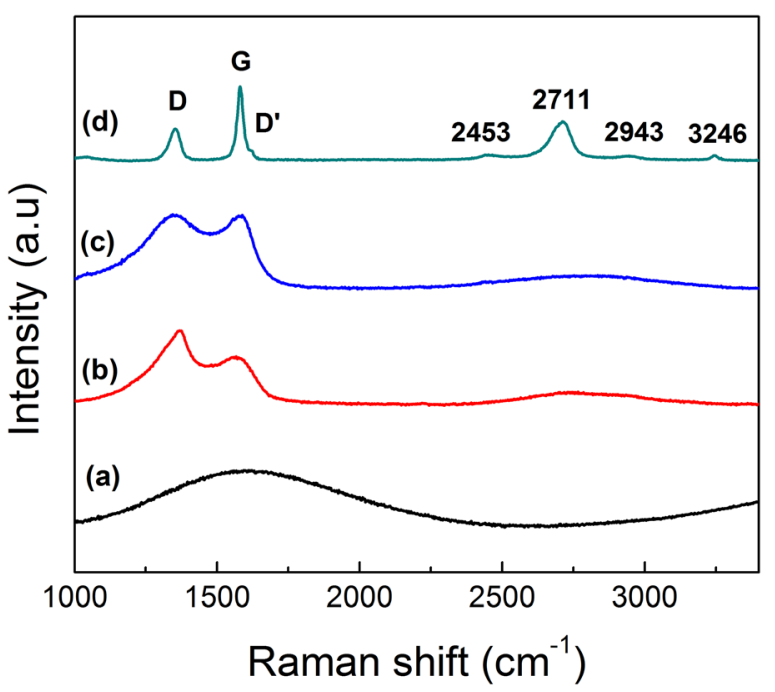

FIG. 4. Raman spectra of PAN fibers at four different stages: (a) electrospun PAN fibers, (b) stabilized PAN fibers, (c) furnace carbonized PAN fibers, and (d) MPECVD carbonized PAN fibers with CNW coatings. 
crystallinity). ${ }^{12,17,22}$ As shown in Fig. 4(b) and summarized in Table $\mathrm{I}$, the $R$-value calculated for the present stabilized PAN fibers is 1.6 (sample b).

Fig. 4(c) shows the Raman spectrum of the furnace carbonized PAN fibers. It can be seen that both $D$ band and $G$ band are present, although the relative peak intensity has changed, which results in the decrease of $R$-value to 1 approximately. The decrease in $R$-value implies that the increased crystallinity of the carbon structures has been developed through the carbonization process. In addition, there is a broad band centered at $2835 \mathrm{~cm}^{-1}$.

Fig. 4(d) shows the Raman spectrum of the MPECVD carbonized PAN fibers. By comparing the Raman spectra of sample c and sample d, it can be observed that the Raman peaks assigned to $D$ band $\left(1353 \mathrm{~cm}^{-1}\right)$ and $G$ band $\left(1581 \mathrm{~cm}^{-1}\right)$ are much shaper, with several additional weak peaks appearing at $1621 \mathrm{~cm}^{-1}, 2453 \mathrm{~cm}^{-1}, 2711 \mathrm{~cm}^{-1}$, $2943 \mathrm{~cm}^{-1}$, and $3246 \mathrm{~cm}^{-1}$. The weak peak at $1621 \mathrm{~cm}^{-1}$ corresponds to $D^{\prime}$ band and is induced by disorder. ${ }^{3}$ Such disorder could be resulted from the low crystallinity of carbonized PAN fibers (i.e., sample d), due to the relatively low carbonization temperature. ${ }^{12,17,22,23}$ As we discussed before, sample d was carbonized at $\sim 750^{\circ} \mathrm{C}$, which is significantly lower than the carbonization temperature $\left(\right.$ at $1000^{\circ} \mathrm{C}$ ) for sample $\mathrm{c}$ when using conventional furnace method. Therefore, sample d shows the presence of $D^{\prime}$ band representing the higher level of disorder than sample c.

Other peaks at $2453 \mathrm{~cm}^{-1}, 2711 \mathrm{~cm}^{-1}, 2943 \mathrm{~cm}^{-1}$, and $3246 \mathrm{~cm}^{-1}$ are attributed to the second-order Raman features and have been assigned to the contribution from highly ordered carbon structures. ${ }^{15,24}$ These are unlikely to be derived from the disordered low crystalline carbonized PAN fibers of sample d, but could be originated from the CNWs. Zhu et al. have identified similar Raman peak positions for their CNS as shown in sample d. ${ }^{25}$ In combination with SEM images, it can be concluded that sample d is a carbon hybrid material, containing both low crystalline carbonized PAN fibers and CNWs. Therefore, the Raman spectrum of sample d shows a combined characteristic of both PAN fiber and CNWs.

The ratio of peak intensity of $D$ band $\left(I_{D}\right)$ and $G$ band $\left(I_{G}\right)$, denoted as $R$-value for all samples, is shown in Table $\mathrm{I}$. It can be seen that $R$-value is dropped from 1 for sample $\mathrm{c}$ to 0.4 for sample d. The decrease of $R$-value indicates that the overall quality of sample d (i.e., carbon hybrid material including both carbonized PAN fibers and CNWs) has good crystallinity, and is believed to relate with the presence of $\mathrm{H}_{2}$ plasma during the MPECVD process. ${ }^{24}$ The $\mathrm{H}_{2}$ plasma has

TABLE I. Assignment of main Raman peaks of PAN fibers derived from various treatments. $v_{D}, v_{G}$, and $v_{D}$ are the Raman peak position of $D$ band, $G$ band, and $D^{\prime}$ band, respectively. $I_{D} / I_{G}$ represents $R$-value, is the intensity ratio of $D$ band to $G$ band.

\begin{tabular}{lcccc}
\hline \hline Sample & $v_{D}\left(\mathrm{~cm}^{-1}\right)$ & $v_{G}\left(\mathrm{~cm}^{-1}\right)$ & $v_{D^{\prime}}\left(\mathrm{cm}^{-1}\right)$ & $I_{D} / I_{G}$ \\
\hline $\mathrm{a}$ & $\ldots$ & $\ldots$ & $\ldots$ & $\ldots$ \\
$\mathrm{b}$ & 1374 & 1567 & $\ldots$ & 1.6 \\
$\mathrm{c}$ & 1344 & 1588 & $\ldots$ & 1 \\
$\mathrm{~d}$ & 1353 & 1581 & 1621 & 0.4 \\
\hline \hline
\end{tabular}

proven to be effective in promoting the crystallinity of the carbon materials as explained by the following factors: (1) atomic hydrogen can preferentially etch amorphous phase and (2) atomic hydrogen can induce the crystallization. ${ }^{13,24}$

\section{CONCLUSIONS}

We have reported the use of MPECVD as an alternative method to carbonize the electrospun PAN precursors in order to fabricate CFs. Scanning electron microscopy, Raman spectroscopy, and Fourier transform infrared spectroscopy have been used to characterize the fibers at different stages of evolution. It was found that the MPECVD-carbonized PAN fibers do not exhibit any significant change in the fiber diameter, whilst the furnace-carbonized PAN fibers show a $33 \%$ reduction in the fiber diameter. FTIR spectra indicate that there are few functional groups present in either the furnace-carbonized PAN fibers or the MPECVD-carbonized PAN fibers due to the high absorbance of carbon products. An additional coating of CNWs was formed on the surface of the MPECVD-carbonized PAN fibers without the assistance of any metallic catalysts. The characteristic Raman spectra for the CNWs were discussed in detail. The paper presented here will have a potential to develop a novel, economical, and straightforward approach towards mass production of carbon fibrous hybrid materials containing CNWs.

\section{ACKNOWLEDGMENTS}

The authors wish to acknowledge the funding for this research provided by the Science Research Investment Fund (SRIF) via Aston University. The School of Engineering and Applied Science at Aston University is acknowledged for a Ph.D. studentship to Mr. S. Su and an ORS award to Miss. J. Li.

${ }^{1}$ Y. Wu, P. Qiao, T. Chong, and Z. Shen, Adv. Mater. 14(1), 64 (2002).

${ }^{2}$ M. Hiramatsu and M. Hori, Carbon Nanowalls: Synthesis and Emerging Applications (Springer Wien New York, 2010).

${ }^{3}$ S. Kurita, A. Yoshimura, H. Kawamoto, T. Uchida, K. Kojima, M. Tachibana, P. Molina-Morales, and H. Nakai, J. Appl. Phys. 97(10), 104320 (2005).

${ }^{4}$ N. G. Shang, F. C. K. Au, X. M. Meng, C. S. Lee, I. Bello, and S. T. Lee, Chem. Phys. Lett. 358(3-4), 187 (2002)

${ }^{5}$ J. J. Wang, M. Y. Zhu, R. A. Outlaw, X. Zhao, D. M. Manos, B. C. Holloway, and V. P. Mammana, Appl. Phys. Lett. 85(7), 1265 (2004).

${ }^{6}$ N. Lisi, R. Giorgi, M. Re, T. Dikonimos, L. Giorgi, E. Salernitano, S. Gagliardi, and F. Tatti, Carbon 49(6), 2134 (2011).

${ }^{7}$ M. S. A. Rahaman, A. F. Ismail, and A. Mustafa, Polym. Degrad. Stab. 92(8), 1421 (2007).

${ }^{8}$ F. L. Paulauskas, K. D. Yarborough, and T. T. Meek, U.S. Patent No. 6,372,192 (16 April 2002).

${ }^{9}$ A. Greiner and J. H. Wendorff, Angew. Chem., Int. Ed. 46(30), 5670 (2007).

${ }^{10}$ W. Zhang, Y. Wang, and C. Sun, J. Polym. Res. 14(6), 467 (2007).

${ }^{11}$ Z. Zhou, C. Lai, L. Zhang, Y. Qian, H. Hou, D. H. Reneker, and H. Fong, Polymer 50(13), 2999 (2009).

${ }^{12}$ M. Panapoy, A. Dankeaw, and B. Ksapabutr, Thammasat Int. J. Sc. Tech. 13, 11 (2008).

${ }^{13}$ M. Zhu, J. Wang, B. C. Holloway, R. A. Outlaw, X. Zhao, K. Hou, V. Shutthanandan, and D. M. Manos, Carbon 45(11), 2229 (2007).

${ }^{14}$ M. Hiramatsu, K. Shiji, H. Amano, and M. Hori, Appl. Phys. Lett. 84(23), 4708 (2004).

${ }^{15}$ S. Vizireanu, B. Mitu, C. R. Luculescu, L. C. Nistor, and G. Dinescu, Surf. Coat. Technol. 211, 2 (2012). 
${ }^{16}$ S. Dalton, F. Heatley, and P. M. Budd, Polymer 40(20), 5531 (1999).

${ }^{17}$ J. Rafique, J. Yu, X. Zha, and K. Rafique, Bull. Mater. Sci. 33, 553 (2010).

${ }^{18}$ S. N. Arshad, M. Naraghi, and I. Chasiotis, Carbon 49(5), 1710 (2011).

${ }^{19}$ Y. Wang, J. Liu, and J. Y. Liang, Adv. Mater. Res. 11-12, 73 (2006).

${ }^{20}$ H. Kakida and K. Tashiro, Polym. J. 29(7), 557 (1997).

${ }^{21}$ J. Sutasinpromprae, S. Jitjaicham, M. Nithitanakul, C. Meechaisue, and P. Supaphol, Polym. Int. 55(8), 825 (2006).
${ }^{22}$ C. Kim, S. H. Park, J. I. Cho, D. Y. Lee, T. J. Park, W. J. Lee, and K. S. Yang, J. Raman Spectrosc. 35(11), 928 (2004).

${ }^{23}$ N. Melanitis, P. L. Tetlow, and C. Galiotis, J. Mater. Sci. 31(4), 851 (1996).

${ }^{24}$ S. Vizireanu, S. D. Stoica, B. Mitu, M. A. Husanu, A. Galca, L. Nistor, and G. Dinescu, Appl. Surf. Sci. 255(10), 5378 (2009).

${ }^{25}$ M. Zhu, J. Wang, R. A. Outlaw, K. Hou, D. M. Manos, and B. C. Holloway, Diamond Relat. Mater. 16(2), 196 (2007). 